\title{
A Printed Monopole Antenna for Triple-Band WLAN/WiMAX Applications
}

\author{
Huiqing Zhai, Lu Liu, Zhihui Ma, and Changhong Liang \\ National Key Laboratory of Antennas and Microwave Technology, School of Electronic Engineering, Xidian University, \\ No. 2 South Taibai Road, Xian, Shaanxi 710071, China \\ Correspondence should be addressed to Huiqing Zhai; hqzhai@mail.xidian.edu.cn
}

Received 4 July 2014; Accepted 9 January 2015

Academic Editor: Tamer S. Ibrahim

Copyright (C) 2015 Huiqing Zhai et al. This is an open access article distributed under the Creative Commons Attribution License, which permits unrestricted use, distribution, and reproduction in any medium, provided the original work is properly cited.

A new compact design of monopole antenna for triple-band WLAN/WiMAX applications with two band-notches based on broadband antenna is presented. By introducing a stub loaded ground and two new paper clip structures etched on radiation patch, a compact overall dimension $31 \mathrm{~mm} \times 33 \mathrm{~mm} \times 1 \mathrm{~mm}$ and three separated operating bands effectively covering $2.4 / 5.2 / 5.8 \mathrm{GHz}$ WLAN bands and 2.5/3.5/5.5 GHz WiMAX bands can be achieved. Compared with familiar U type slot, the introduced compact paper clip structure can save about $37 \%$ of dimension regions, which could effectively improve efficiency of band-notch formation. Simulated and measured results demonstrate that the proposed antenna has good dipole-like radiation characteristics with appreciable gain across the operating bands. Besides, main parameters of the two etched paper clip structures are investigated to control the positions and bandwidths of the two stop-bands, respectively, on basis of which the three working bands can be adjusted independently.

\section{Introduction}

Nowadays, in order to satisfy the ever-growing requirements of miniaturized size, multiband, and omnidirectional pattern antenna for multisystem, a great number of significant researches and designs have been undertaken, especially for the Wireless Local Area Network (WLAN: 2.4-2.48, 5.15-5.35, and 5.72-5.85 GHz) and the Worldwide Interoperability for Microwave Access (WiMAX: 2.5-2.69, 3.403.69 , and $5.25-5.85 \mathrm{GHz}$ ) in the modern communication systems. Compared with the broadband antenna, the multiband antenna can effectively filtrate the unnecessary bands $[1,2]$, which will reduce the system interference and complex for multimode operations. As a result, various kinds of multiband antennas including dual-band and triple-band antennas with different structures, such as those in [3-11], have been proposed to meet the applications for both multiband wireless communication systems. Firstly, two bands were involved in [3] by using a pair of multibranch strips in the radiator; a coplanar waveguide- $(\mathrm{CPW}-)$ fed printed monopole antenna with an n-shaped slot for dual-band operation was proposed in [4] and a complementary electric field coupled (CELC) resonator was loaded in the ground plane of a conventional patch antenna to achieve dualband operation in [5]. Furthermore, in [6-11], some triband antennas have been presented. A single-cell metamaterial loading was introduced to design triple-band monopole antenna in [6]. A cavity-backed slot antenna was presented for triple-band wireless communication in [7] by a wide Zlike slot replacing the traditional rectangular slot. A coplanar waveguide- (CPW-) fed planar monopole antenna with two bent slots for WiMAX and WLAN applications was also proposed in [8]. However, only two bands were involved in [3-5]; the Y-shaped monopole antenna in [6] did not cover the 5.2 $(5.15-5.35 \mathrm{GHz})$ WLAN and $5.5(5.25-5.85 \mathrm{GHz})$ WiMAX bands, and only triple WLAN band operation was included in [7], which reduced their application in the multimode portable devices. The designed antenna in [8] was inspired by TL-MTM work and cutting an L-shaped slot on the ground, which might increase the cost or complexity for practical design. The overall dimensions of the antennas were with large sizes $54 \mathrm{~mm} \times 55 \mathrm{~mm} \times 1 \mathrm{~mm}$ in [9], 


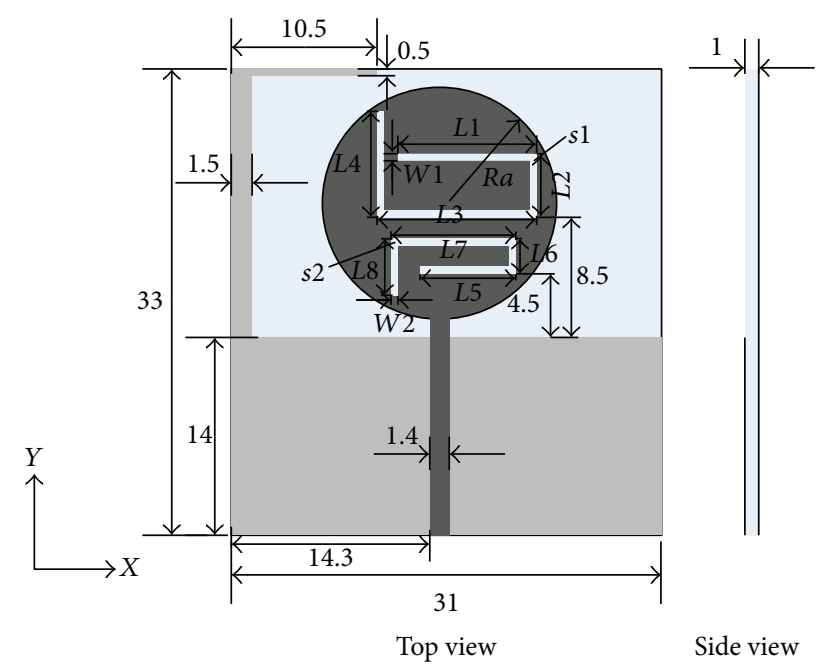

FIGURE 1: Configuration of the presented antenna (units in $\mathrm{mm}$ ) ( $L 1$ $=10 \mathrm{~mm}, L 2=4.5 \mathrm{~mm}, L 3=11.5 \mathrm{~mm}, L 4=7.5 \mathrm{~mm}, L 5=6.9 \mathrm{~mm}, L 6$ $=2.5 \mathrm{~mm}, L 7=9 \mathrm{~mm}, L 8=4 \mathrm{~mm}, \mathrm{Ra}=8.2 \mathrm{~mm}, W 1=0.5 \mathrm{~mm}$, and $W 2=0.5 \mathrm{~mm})$.

$41.5 \mathrm{~mm} \times 27 \mathrm{~mm} \times 1 \mathrm{~mm}$ in [10], and $52 \mathrm{~mm} \times 26 \mathrm{~mm} \times$ $0.5 \mathrm{~mm}$ in [11], which somehow limited the integrated design in compact wireless communication system.

In this research, a new compact design of triple-band printed antenna for WLAN/WiMAX applications is proposed by using two band-notches on basis of broadband antenna. As the introduction of two novel compact etched paper clip structures and a stub loaded ground, a compact overall dimension $31 \mathrm{~mm} \times 33 \mathrm{~mm} \times 1 \mathrm{~mm}$ and three separated operating bands effectively covering $2.4 / 5.2 / 5.8 \mathrm{GHz}$ WLAN bands and $2.5 / 3.5 / 5.5 \mathrm{GHz}$ WiMAX bands can be achieved. The results of measurement show that the antenna can well cover three separated impedance bandwidths of $620 \mathrm{MHz}(2.34-2.96 \mathrm{GHz}), 780 \mathrm{MHz}(3.19-3.97 \mathrm{GHz})$, and $940 \mathrm{MHz}(4.92-5.86 \mathrm{GHz})$, which satisfy the requirements of both $2.4 / 5.2 / 5.8 \mathrm{GHz}$ WLAN bands and $2.5 / 3.5 / 5.5 \mathrm{GHz}$ WiMAX bands. Meanwhile, the antenna has good radiation pattern performance and stable gains in the three working frequency bands. Moreover, both the working positions and the bandwidths of the notched bands can be tuned, respectively, which will help it perform better in more flexible multimode design and application.

\section{Design and Analysis of the Present Antenna}

Figure 1 shows the geometries of the proposed three-band monopole antenna for WLAN and WiMAX applications, which includes two new etched paper clip structures $s 1$ and $s 2$ on the radiation patch and a stub loaded ground. These two slots are etched with a width of $0.5 \mathrm{~mm}$. The present antenna is fed with $50 \Omega$ microstrip line and fabricated on a $1 \mathrm{~mm}$ thick FR4 substrate with a relative permittivity of 4.4 and a loss tangent of 0.02 . The radiation element and microstrip feed line shift $0.5 \mathrm{~mm}$ to the left side of the substrate for better impedance matching. The above corresponding parameters are achieved by commercial simulation software

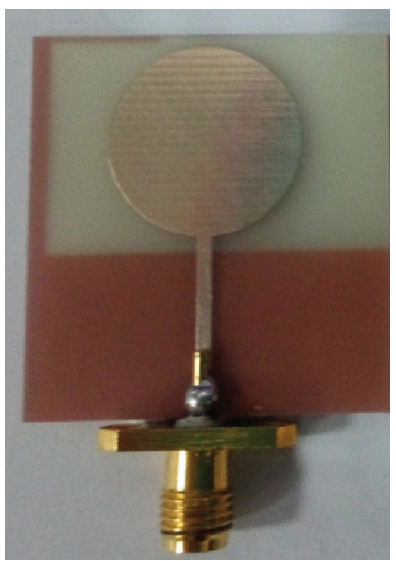

(a)

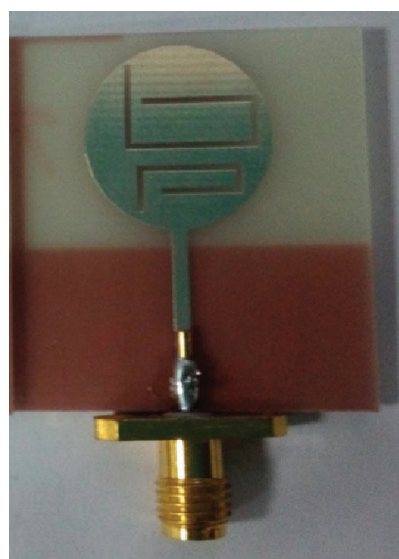

(b)
FIGURE 2: Fabricated prototypes. (a) The compact broadband antenna. (b) The proposed triple-band antenna.

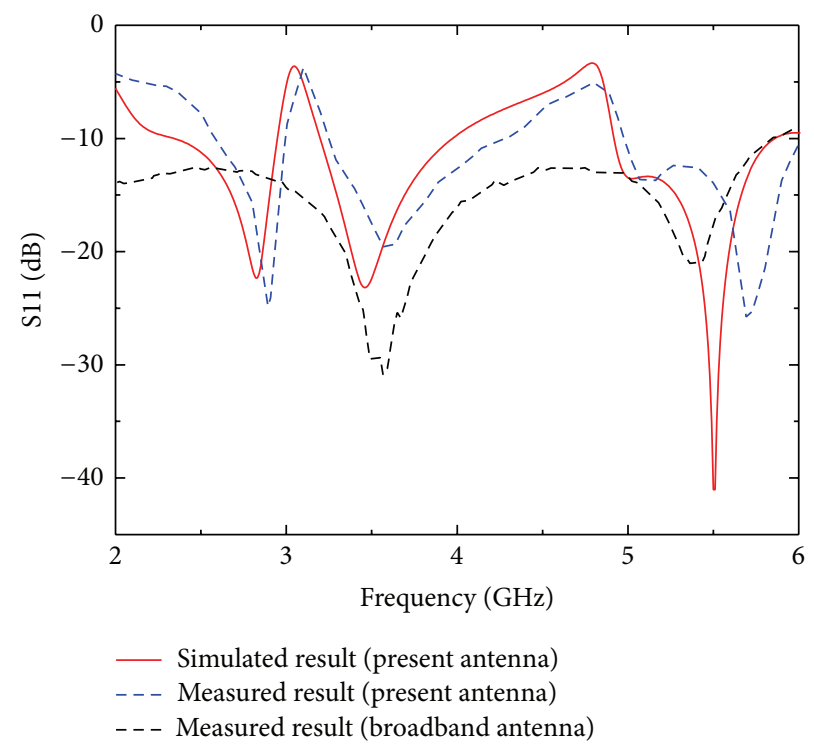

FIGURE 3: The simulated and measured return loss of the present triple-band antenna and broadband antenna.

HFSS [12]. The practical fabricated two antennas, including a present triple-band antenna and broadband antenna for the reference, are displayed in Figures 2(a) and 2(b).

The simulated and measured results of the proposed broadband antenna and triple-band antenna are presented in Figure 3. We can observe, respectively, that the measured results, which were performed by using a vector network analyzer (Agilent 8719ES), have good agreement with the simulated results. The small shift between measured and simulated values mainly due to the fabrication and measurement error and the influence of the SMA port is also not considered. Besides, the original broadband antenna for reference works from $2.8 \mathrm{GHz}$ to $5.7 \mathrm{GHz}$ and the proposed tripleband antenna can effectively cover three separated impedance 


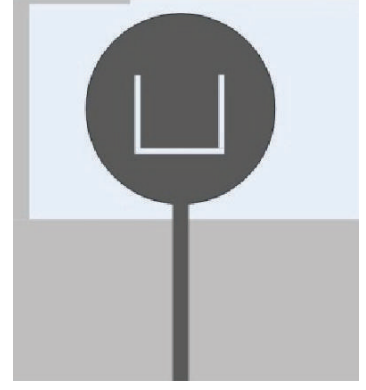

(a) U type slot

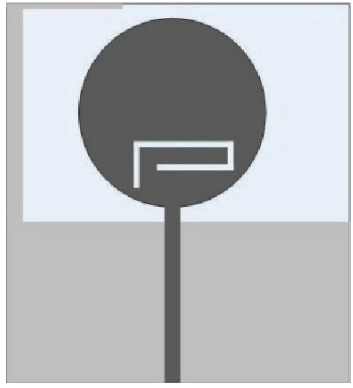

(b) Clip type slot

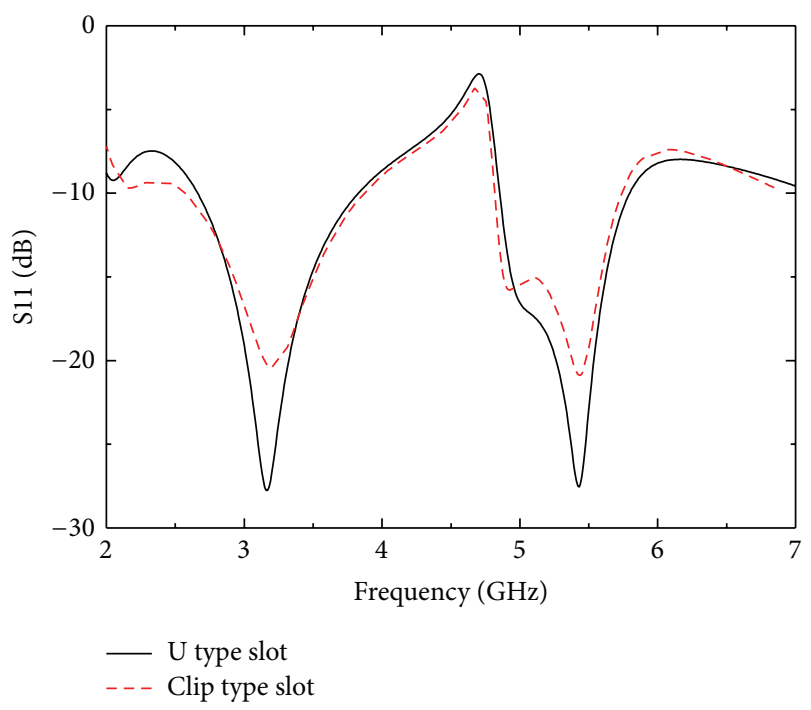

(c)

FIGURE 4: The performance of band-notch formation for two type slots.

bandwidths of $2.34-2.96 \mathrm{GHz}, 3.19-3.97 \mathrm{GHz}$, and $4.92-$ $5.86 \mathrm{GHz}$, which can effectively cover $2.4 / 5.2 / 5.8 \mathrm{GHz}$ WLAN bands and $2.5 / 3.5 / 5.5 \mathrm{GHz}$ WiMAX bands. Moreover, two stop-bands can be found at about 2.96-3.19 GHz and 3.97$4.92 \mathrm{GHz}$ from the simulated results in Figure 3.

In Figure 4, we make a comparison of clip type slot and $\mathrm{U}$ type slot to illustrate the improvement of the designed clip slot. In the condition of the same length, the antenna with the two different slots can reach almost the same center-rejected frequency point and bandwidth of the notched bands, as is shown in Figure 4, which indicate that the antenna with clip type slot obviously becomes smaller. In detail, the dimensions of the etched clip type slot and the $U$ type slot are $9 \mathrm{~mm}$ $\times 3.9 \mathrm{~mm}$ and $8 \mathrm{~mm} \times 7 \mathrm{~mm}$, respectively. As a result, the dimensions of the clip type slot have a practical decrease for $37 \%$. Thus, the presented radiator with clip type slot could effectively improve efficiency of band-notch formation.

To demonstrate the positive effect of the stub loaded ground plane, we make a comparison on the antennas with and without the loaded stub, as is depicted in Figure 5. We can clearly find that the first operating band is decreased from $2.9-3.1 \mathrm{GHz}$ to $2.34-2.96 \mathrm{GHz}$ when loading the Lshaped stub. The equivalent inductance on the ground plane

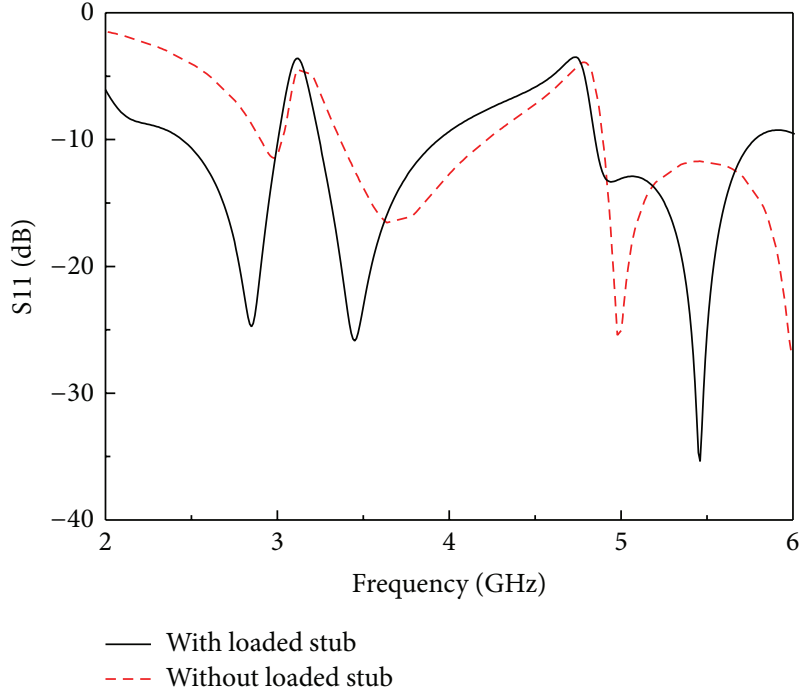

FIGURE 5: The simulated return loss of the two antennas.

is enlarged with the loaded stub, which results in the decrease of the resonance frequency and enables us to achieve the miniaturization of the antenna [13].

Actually, the introduction of etched paper clip structures makes two band-notches for the original broadband antenna. The frequency of band-notch can be empirically approximated by

$$
f=\frac{c}{2 \sqrt{\left(\varepsilon_{r}+1\right) / 2} \cdot L_{\text {total }}},
$$

where $c$ is the speed of light in free space, $\varepsilon_{r}$ is the relative permittivity, and $L_{\text {total }}$ is the total length of the etched paper clip slot [14], so the initial length of the two slots can be calculated by (1). Therefore, by carefully designing the lengths of these slots, the resonant frequency can easily match the desired frequency and good dual stop-band rejection characteristic of the antenna can be obtained. Through simulation and optimization, we get the values $L_{s 1}=L 1+L 2+L 3+L 4=$ $33.5 \mathrm{~mm}$ and $L_{s 2}=L 5+L 6+L 7+L 8=22.4 \mathrm{~mm}$, which are approximately a quarter of the guided wavelength calculated at the two resonant frequency points, respectively.

To investigate the operation mechanism of slots $s 1$ and $s 2$, the simulated S11 of the introduced different slots and the current distributions on radiation patches are shown in Figures 6 and 7, respectively. It can be clearly seen in Figure 5 that the two new etched paper clip slots $s 1$ and $s 2$ play an important role as two band-notched filters to block the limited band as is expected. Moreover, Figure 5 reveals that the bigger clip slot $s 1$ and the smaller clip slot $s 2$ each creates a corresponding notched band. The first stop-band is achieved by using slot $s 1$ and the second stop-band is achieved by using slot $s 2$. The weaker couplings of the two etched slots make us expect that the notch frequency without slot $s 1$ or $s 2$ can effectively estimate the position of notch frequency for the present antenna with slots $s 1$ and $s 2$.

In order to further show graphic understanding on the affections of the etched paper clip structures, the current 


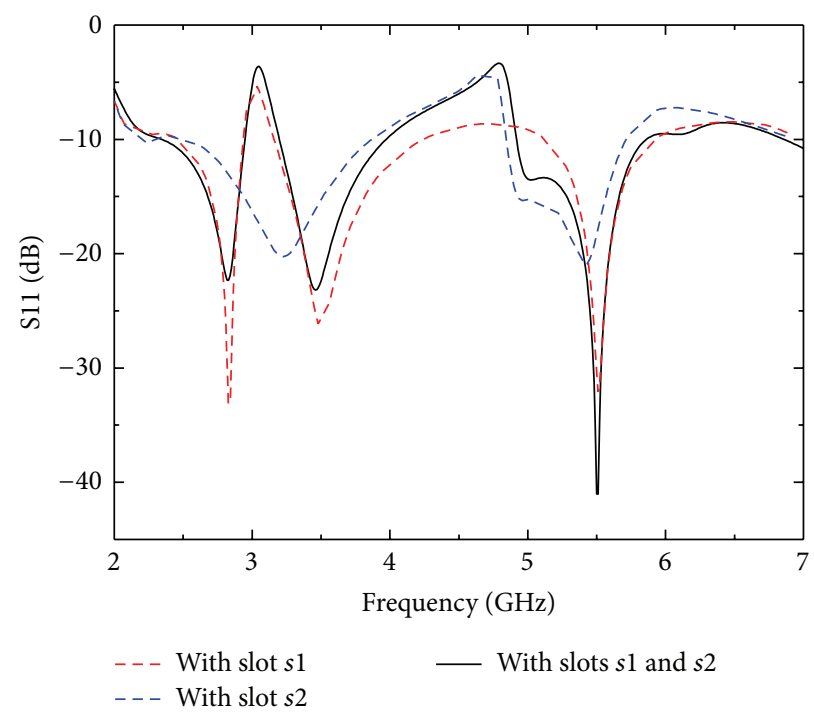

FIGURE 6: Comparisons of the introduced different slots on the return loss of the antenna.

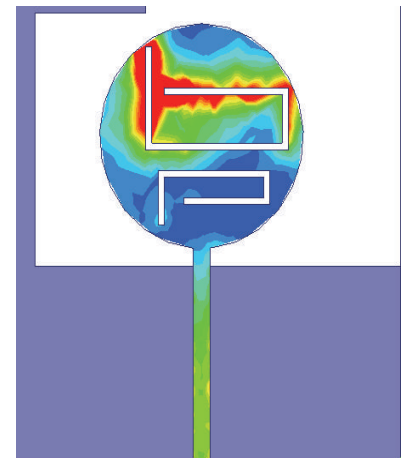

(a)

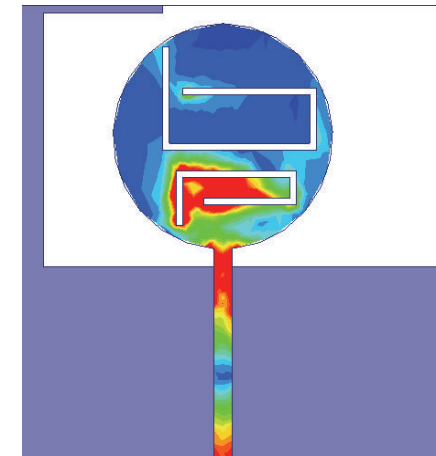

(b)

FIgURE 7: The current distributions on radiation patches. (a) Current distributions for band-notch at 3.0 GHz. (b) Current distributions for band-notch at $4.8 \mathrm{GHz}$.

distributions on radiation patches at frequencies 3.0 and $4.8 \mathrm{GHz}$ are also displayed in Figure 7. From Figure 7(a), we can see that the strong current distribution is along slot $s 1$, which indicates that slot $s 1$ is the major radiating element to produce the first band-notch. In Figure 7(b), larger current distribution is observed at slot $s 2$, which means that it provides main contribution for band-notch at $4.8 \mathrm{GHz}$ and the second resonance mode has been excited.

The simulated and measured normalized radiation patterns for $y-z$ plane and $x-z$ plane at $2.5 / 3.5 / 5.5 \mathrm{GHz}$ are plotted in Figure 8, respectively. It can be observed that nearly omnidirectional patterns are obtained for all three frequency bands in $x-z$ plane, and close to bidirectional patterns in $y-z$ plane are achieved.

Figure 9 shows the simulated and measured maximum gain of the proposed antenna. We can see that the gain falls sharply at near 3.0 and $4.8 \mathrm{GHz}$ as most of the radiated power is reflected at the notch bands, from which we can conclude that the antenna exhibits stable gains in three working frequency bands. It should be noted that some shifts between simulated and measured results can be found because of the fabricated and measurement error.

\section{Parameters Analysis}

In this section, the main physical parameters will be investigated to show the flexible design of two notch bands, on basis of which the three working bands can be effectively designed according to the positions and bandwidths of two notches. Firstly, the lengths of the two slots will be changed to analyze their effect on the antenna's return loss S11, which is shown in Figure 10.

By selecting different values of the main parameters carefully, the tunable characteristic for the first and second stop-band can be achieved, respectively. In Figure 10(a), when changing the parameters from statel to state3, the antenna shows a tunable centre-rejected frequency ranging from 3.06 GHz to $3.25 \mathrm{GHz}$ for the first stop-band, while the second stop-band is almost unchanged. In addition, by changing the value of $L 7$ from $7.5 \mathrm{~mm}$ to $8.5 \mathrm{~mm}$, the centre-rejected 


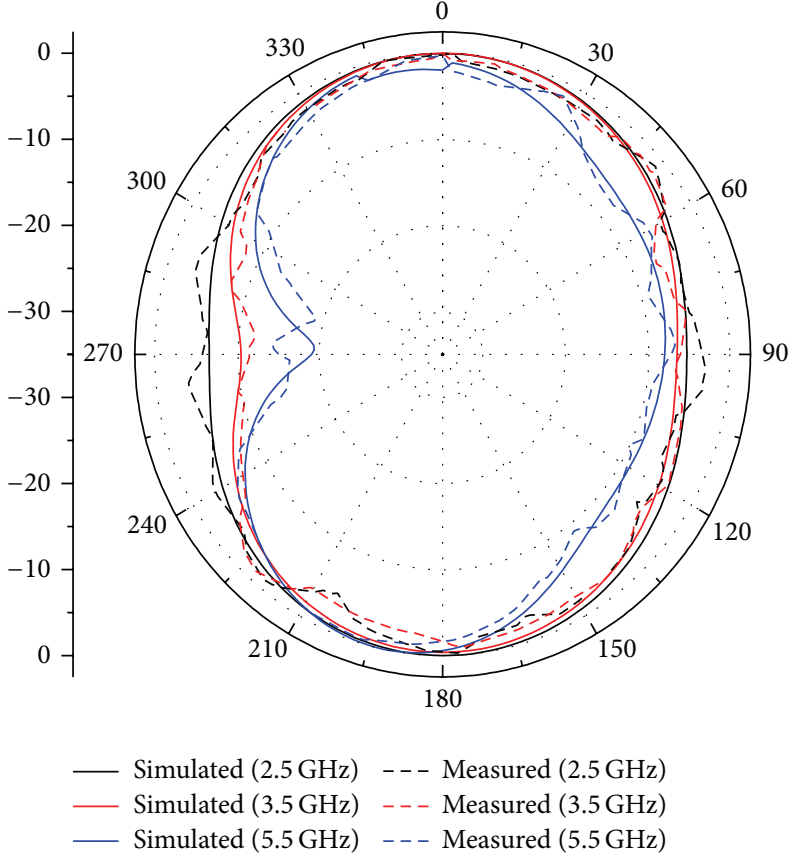

(a)

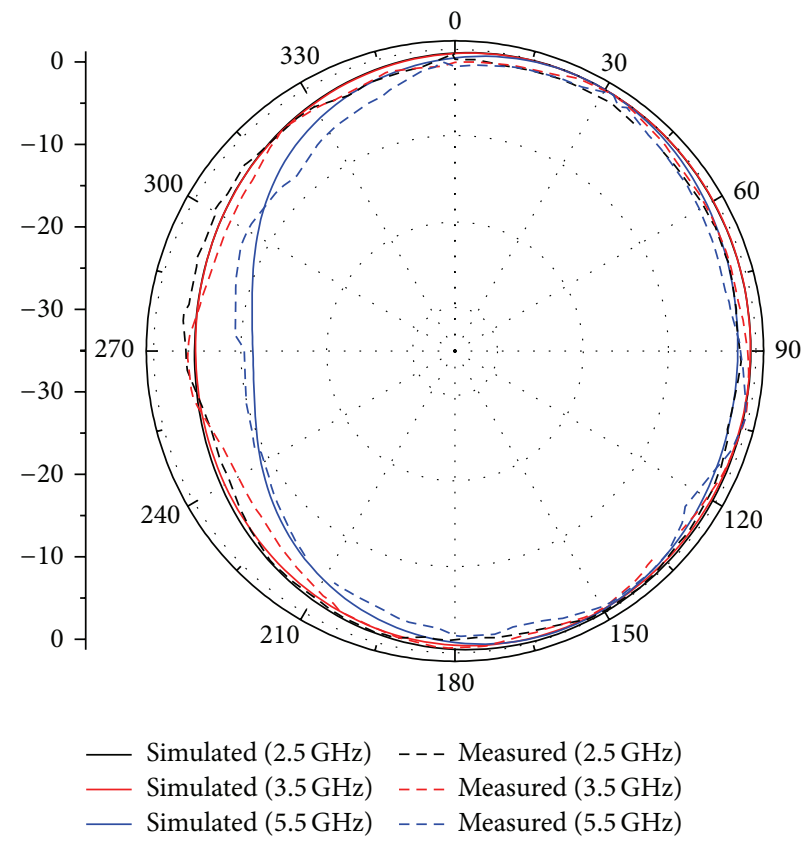

(b)

FIGURE 8: Simulated and measured normalized radiation patterns. (a) Simulated and measured normalized $y$ - $z$ plane at 2.5/3.5/5.5 GHz. (b) Simulated and measured normalized $x-z$ plane at $2.5 / 3.5 / 5.5 \mathrm{GHz}$.

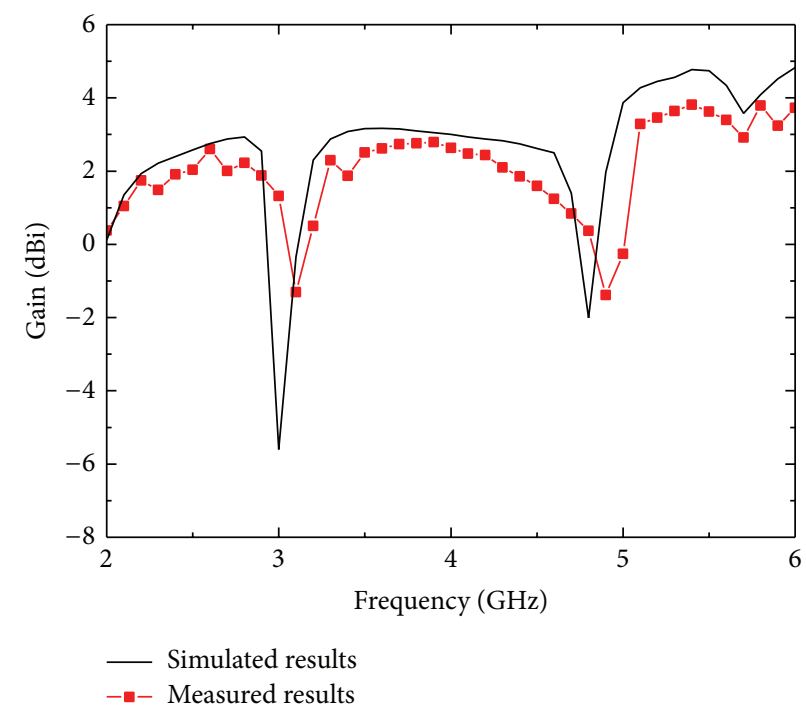

FIGURE 9: Simulated and measured gains of the proposed antenna in three working bands (unit: dBi).

frequency for the second stop-band varies from $4.72 \mathrm{GHz}$ to $4.92 \mathrm{GHz}$ when the first stop-band keeps nearly stable, which is plotted in Figure 10(b).

Secondly, the bandwidth of two notches will be discussed by the corresponding parameters. Figure 11 depicts the effect of varying parameters on the bandwidths of the notched bands. It can be seen that bandwidths of the two notched bands can be effectively adapted when the scales of the two slots are changed from state 7 to state 9 and from state10 to state12, respectively. In Figure 11(a), the bandwidth is changed by the parameters $L 1, L 2, L 3$, and $W 1$ while the second stopband almost keeps steady as the parameters vary from state7 to state9. In Figure 11(b), when changing the parameters from state10 to state12, in which the parameters L5, L6, L7, and $W 2$ are optimized, the second stop-band also has an adjustable bandwidth with the first one being nearly unchanged. Totally, the tunable properties of the antenna along with the parameters' changes are very helpful for 


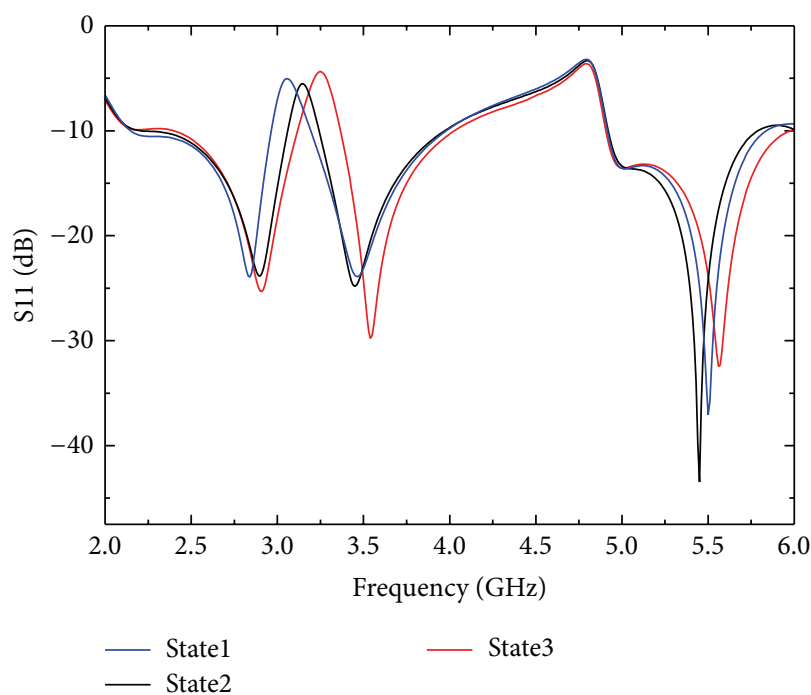

(a)

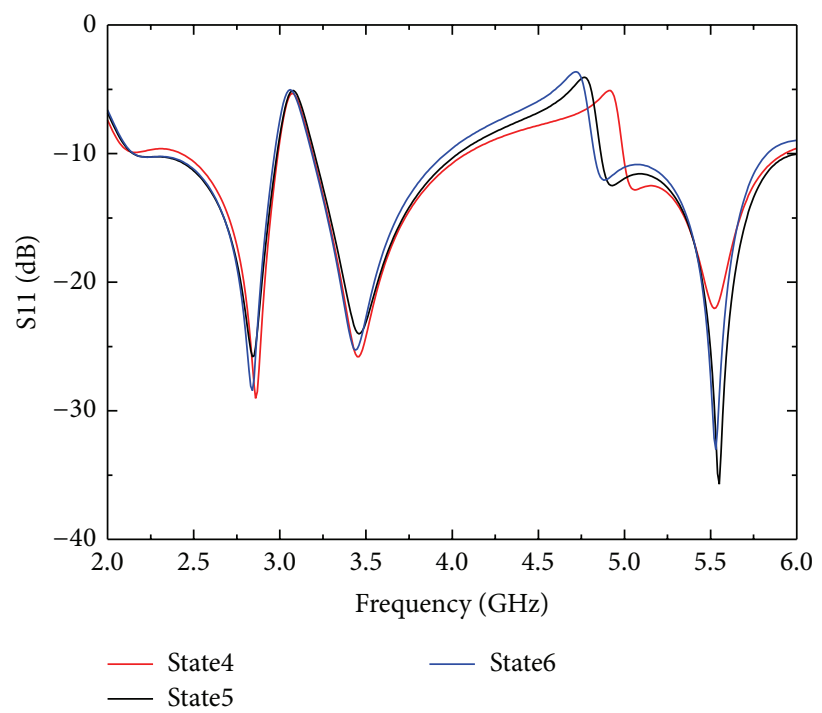

(b)

Figure 10: (a) Simulated results of the band-rejected feature against various lengths for slot $s 1$ (state1: $L 1=10 \mathrm{~mm}, L 4=8.7 \mathrm{~mm}$; state2: $L 1=$ $10 \mathrm{~mm}, L 4=6.9 \mathrm{~mm}$; state $3: L 1=9 \mathrm{~mm}, L 4=6.9 \mathrm{~mm}$ ). (b) Simulated results of the band-rejected feature against various lengths for slot $s 2$ (state4: $L 7=7.5 \mathrm{~mm}$; state5: $L 7=8.5 \mathrm{~mm}$; state6: $L 7=8.5 \mathrm{~mm}$ ).

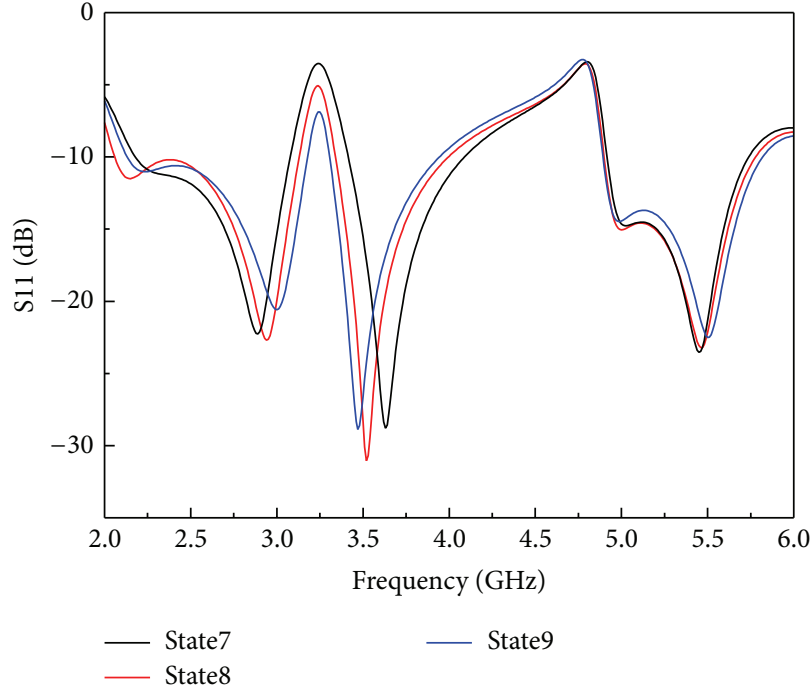

(a)

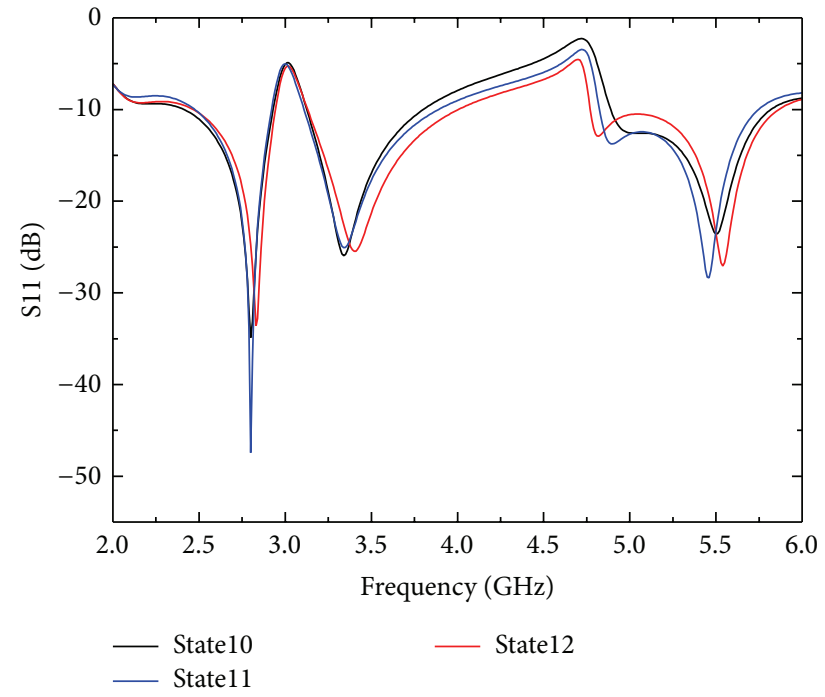

(b)

FIGURE 11: Effect of varying parameters on the amplitude and bandwidth of the notched bands: (a) length of the slot $s 1$ (state7: $L 1=8.5 \mathrm{~mm}$, $L 2=4.9 \mathrm{~mm}, L 3=11.5 \mathrm{~mm}$, and $W 1=0.5 \mathrm{~mm}$; state $8: L 1=8.5 \mathrm{~mm}, L 2=4.7 \mathrm{~mm}, L 3=10.5 \mathrm{~mm}$, and $W 1=0.3 \mathrm{~mm} ; \mathrm{state} 9: L 1=9 \mathrm{~mm}, L 2=$ $4.3 \mathrm{~mm}, L 3=10 \mathrm{~mm}$, and $W 1=0.3 \mathrm{~mm}$ ); (b) length of slot $s 2$ (state10: $L 5=6.6 \mathrm{~mm}, L 6=2.5 \mathrm{~mm}, L 7=10 \mathrm{~mm}$, and $W 2=0.5 \mathrm{~mm}$; state11: $L 5$ $=7 \mathrm{~mm}, L 6=2.8 \mathrm{~mm}, L 7=8.5 \mathrm{~mm}$, and $W 2=0.5 \mathrm{~mm}$; state12: $L 5=6.8 \mathrm{~mm}, L 6=2.8 \mathrm{~mm}, L 7=7.5 \mathrm{~mm}$, and $W 2=0.4 \mathrm{~mm}$ ).

flexible designs of three tunable working bands, which is a better candidate for compact multimode terminal design in wireless communication system.

\section{Conclusion}

In this paper, a new compact triple-band printed antenna has been designed and implemented by two band-notches on basis of broadband antenna. The introduction of compact etched paper clip structure can effectively save the etched dimension regions. In the present antenna design, three separated operating bands well cover tripleband WLAN/WiMAX applications, which are verified by simulated and measured results. In addition, the parameters of the two etched paper clip structures are investigated to shift the center positions and bandwidths of the two stop-bands, which make the three working bands separately adjusted for more flexible multimode applications. 


\section{Conflict of Interests}

The authors declare that there is no conflict of interests regarding the publication of this paper.

\section{Acknowledgments}

This work is supported by the Natural Science Basic Research Plan in Shaanxi Province of China under Grants nos. 2014JM8316 and 2014JQ8352, the NSFC under Contracts nos. 61101066, 51477126, and 61401335, and the Fundamental Research Funds for the Central Universities under Grant JB140232.

\section{References}

[1] H. F. AbuTarboush, H. S. Al-Raweshidy, and R. Nilavalan, "Triple band double U-slots patch antenna for WiMAX mobile applications," in Proceedings of the 14th Asia-Pacific Conference on Communications (APCC '08), pp. 1-3, 2008.

[2] S. Chaimool and K. L. Chung, "CPW-fed mirrored-L monopole antenna with distinct triple bands for WiFi and WiMAX applications," Electronics Letters, vol. 45, no. 18, pp. 928-929, 2009.

[3] C.-H. Ku, H.-W. Liu, Y.-C. Hsin, K.-Y. Lin, and P.-J. Wang, "Compact planar dual-band folded dipole antenna for WLAN/ WiMAX applications," IEICE Electronics Express, vol. 8, no. 2, pp. 64-69, 2011.

[4] S. T. Fan, Y. Z. Yin, W. Hu, K. Song, and B. Li, "Novel CPW-FED printed monopole antenna with an n-shaped slot for dual-band operations," Microwave and Optical Technology Letters, vol. 54, no. 1, pp. 240-242, 2012.

[5] S. V. Reddy, K. Saurav, D. Sarkar, A. Singh, and K. V. Srivastava, "Design of a novel dual band patch antenna loaded with CELC resonator for WLAN/WiMAX applications," in Proceedings of the 20th National Conference on Communications (NCC '14), pp. 1-6, March 2014.

[6] P. A. Liu, Y. L. Zou, B. R. Xie, X. L. Liu, and B. H. Sun, “Compact $\mathrm{CPW}$-fed tri-band printed antenna with meandering split-ring slot for WLAN/WiMAX applications," IEEE Antennas and Wireless Propagation Letters, vol. 11, pp. 1242-1244, 2012.

[7] Q.-Y. Zhang and Q.-X. Chu, "Triple-band cavity-backed Zlike slot antenna for wlan applications," Microwave and Optical Technology Letters, vol. 51, no. 10, pp. 2296-2301, 2009.

[8] J. Zhu, M. A. Antoniades, and G. V. Eleftheriades, "A compact tri-band monopole antenna with single-cell metamaterial loading," IEEE Transactions on Antennas and Propagation, vol. 58, no. 4, pp. 1031-1038, 2010.

[9] D.-S. Cai, Z.-Y. Lei, H. Chen, G.-L. Ning, and R.-B. Wang, "Crossed oval-ring slot antenna with triple-band operation for WLAN/WiMAX application," Progress in Electromagnetics Research Letters, vol. 27, pp. 141-150, 2011.

[10] Y. Han, Y.-Z. Yin, Y.-Q. Wei, Y. Zhao, B. Li, and X.-N. Li, "A novel triple-band monopole antenna with double coupled C-shaped strips for WLAN/WiMAX applications," Journal of Electromagnetic Waves and Applications, vol. 25, no. 8-9, pp. 1308-1316, 2011.

[11] R. L. Li, X. L. Quan, Y. H. Cui, and M. M. Tentzeris, "Directional triple-band planar antenna for WLAN/WiMax access points," Electronics Letters, vol. 48, no. 6, pp. 305-306, 2012.
[12] Ansoft Corporation, High Frequency Structure Simulator (HFSS), Ansoft Corporation, Pittsburgh, Pa, USA, 2012.

[13] T. Li, H. Q. Zhai, G. H. Li, L. Li, and C. H. Liang, "Compact UWB band-notched antenna design using interdigital capacitance loading loop resonator," IEEE Antennas and Wireless Propagation Letters, vol. 11, pp. 724-727, 2012.

[14] M.-C. Tang, S. Xiao, T. Deng et al., "Compact UWB antenna with multiple band-notches for WiMAX and WLAN," IEEE Transactions on Antennas and Propagation, vol. 59, no. 4, pp. 1372-1376, 2011. 

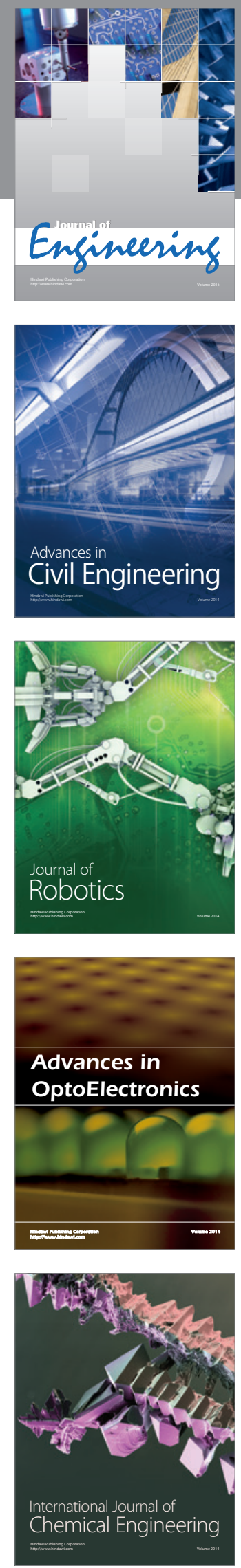

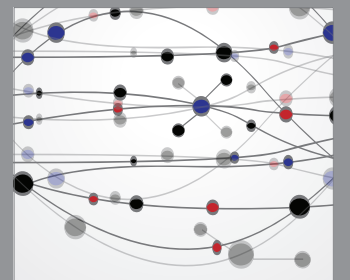

The Scientific World Journal
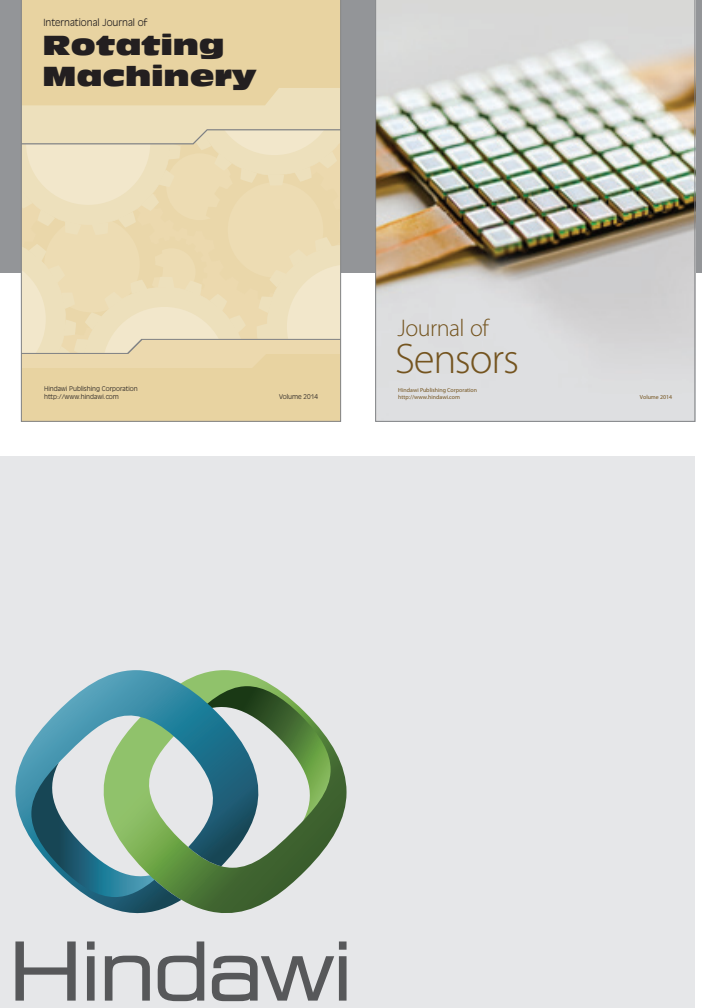

Submit your manuscripts at http://www.hindawi.com
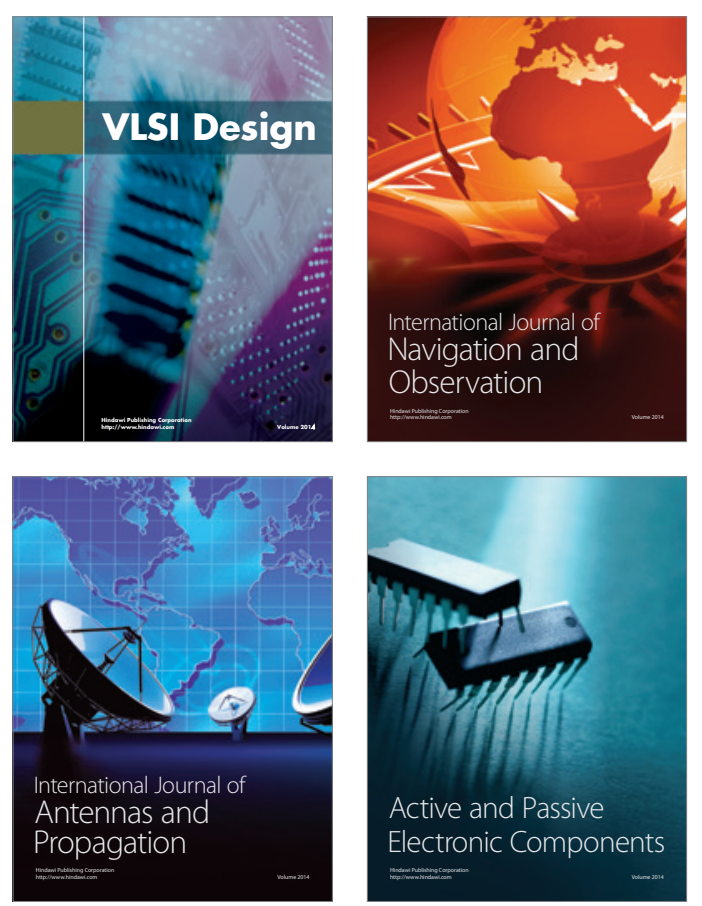
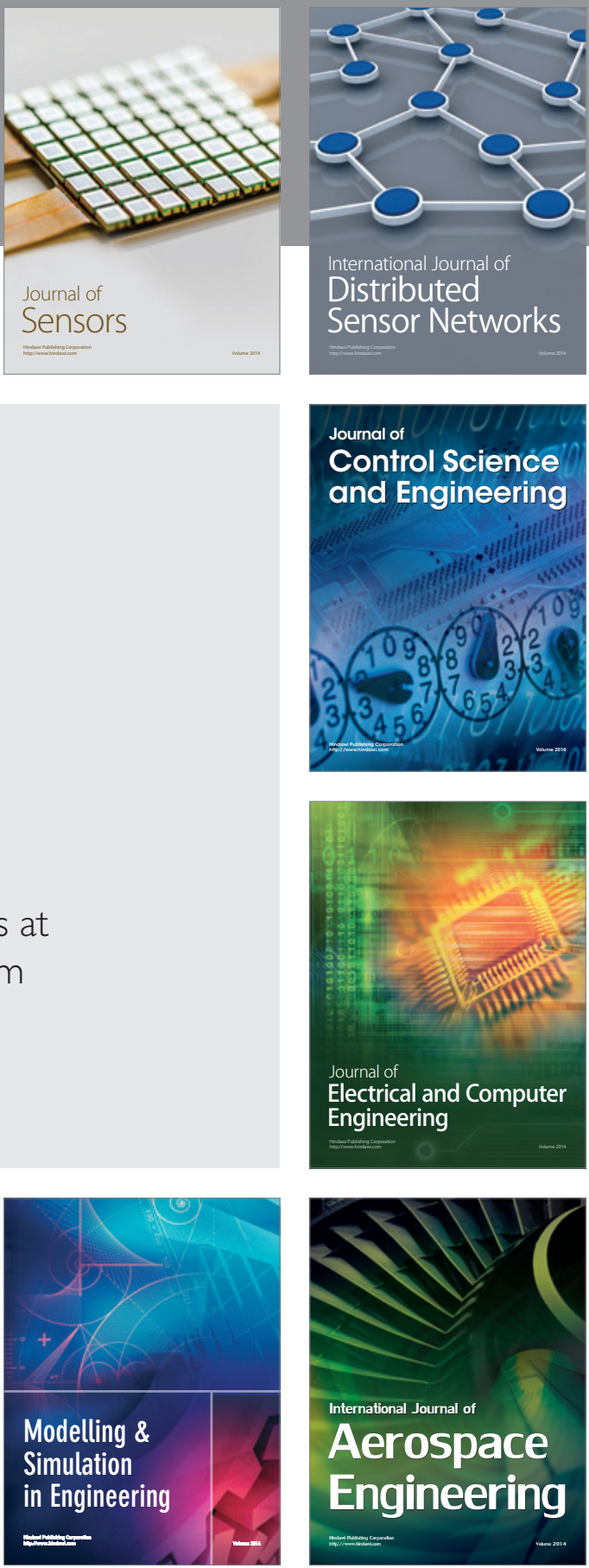

Journal of

Control Science

and Engineering
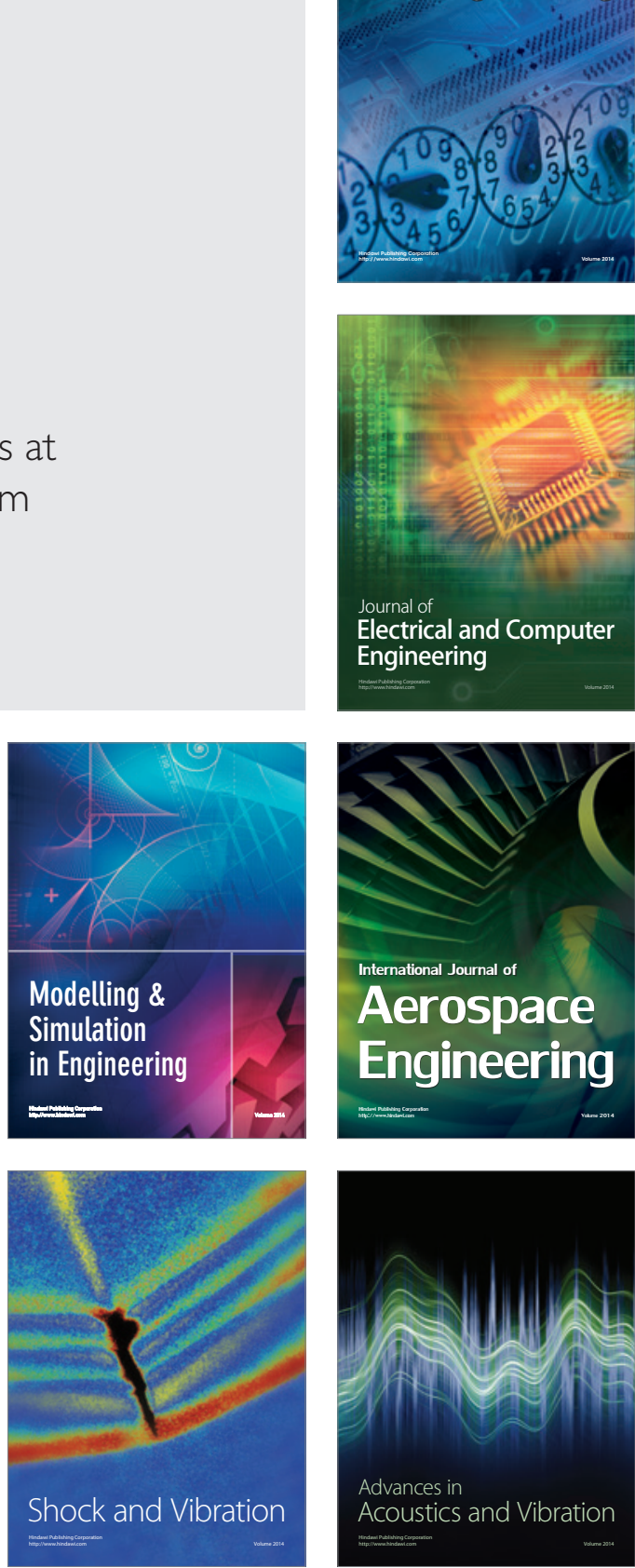